УДК 687.12

\title{
ПРОЕКТИРОВАНИЕ КОСТЮМА С ИСПОЛЬЗОВАНИЕМ ЭВРИСТИЧЕСКИХ И КОМБИНАТОРНЫХ МЕТОДОВ
}

\author{
Джанибекян Виктория Владимировна
}

ст. преподаватель

Уваров Виктор Дмитриевич

д-р искусствоведения, профессор, профессор ФГБОУ ВО «Российский государственный университет им. А.Н. Косыгина (Технологии. Дизайн. Искусство)»

г. Москва

\begin{abstract}
Аннотация: Статья представляет собой попытку дать комплексный анализ деятельности модельеров, применяющих эвристические и комбинаторные методы в художественном проектировании костюма. Комбинаторика «оперирует» определенными приемами комбинирования: перестановкой, вставкой, группировкой, переворотом, организацией ритмов. Прием перестановки, или эвристическое комбинирование, предполагает изменение элементов, их замену. Этот прием получил широкое применение в проектной практике как более простой и дающий достаточно неожиданные результаты. Его можно охарактеризовать как комбинаторный поиск компоновочных решений. Этот прием часто используется при вариантном применении деталей изделия.
\end{abstract}

Ключевые слова: инновации, костюм, авангардный костюм, эвристические методы, комбинаторика.

\section{HEURISTIC AND COMBINATORIAL METHODS IN ARTISTIC COSTUME DESIGN}

\section{Dzhanibekyan Victoria Vladimirovna Uwaroff Victor Dmitrievich}

\footnotetext{
Abstract: The article is an attempt to give a comprehensive analysis of the activities of fashion designers who use heuristic and combinatorial methods in the artistic design of a costume. Combinatorics "operates" with certain methods
} 
of combining: permutation, insertion, grouping, reversal, organization of rhythms. The method of re-setting, or heuristic combination, involves changing elements, replacing them. This technique has been widely used in project practice as simpler and gives quite unexpected results. It can be described as a combinatorial search for layout solutions. This technique is often used in the variant application of product parts.

Key words: innovation, costume, avant-garde costume, heuristic methods, combinatorics.

Мода проникает во все сферы нашей жизни - в каких-то аспектах они неумолима и строга, в других же терпима и благосклонна [1]. В современном, постмодернистском обществе чрезвычайно возросла роль искусства и дизайна как важных механизмов самопознания и эмоционального развития человека. Предметом настоящего исследования выступают эвристические и комбинаторные методы проектирования костюма. Статья представляет собой попытку дать комплексный анализ деятельности модельеров, работающих в этой области искусства костюма.

Цель работы: проведение научного исследования, выявление специфики эвристических методов проектирования костюма и определение направления, в котором необходимо двигаться моде.

Авторами был проведен литературно-аналитический обзор трудов, посвященных данной теме; проанализированы пути развития теории проектирования костюма. В процессе исследования были использованы следующие методы: литературно-аналитический метод, необходимый для изучения биографии модельеров, уточнения отдельных фактов и обобщения информации из литературных источников, предметно-аналитический метод, который необходим для структурного разбора визуальных материалов, поиска композиционных и цветовых особенностей произведений.

Со времен Платона акт мышления воспринимался как логический, сознательный и словесный процесс, а эмоции высмеивались как препятствие для правильного мышления. Кто не слышал поговорку «Думай головой, а не сердцем»? Но в настоящее время выдающиеся нейробиологи всего мира, изучавшие мозг в действии, поместили эмоции на руководящее место, утверждая, что мышление основано на эмоциях. [2].

«Эвристика (от греч. heurisko - обнаруживаю, открываю) - метод, или методологическая дисциплина, предметом которой является решение проблем 
в условиях неопределенности. Главной проблемой эвристики является устранение противоречий. В область эвристики передаются все вторичные, неточные, методологические регулятивы, которые изгоняются из частных наук». [3].

В современной социокультурной среде художники-модельеры заняты поисками новых идей в сфере промышленного проектирования костюма, его формы, структуры и общей эстетики, соответствующих требованиям модных тенденций. Эвристические методы художественного проектирования костюма являются культурным триггером для активации творческого процесса, оказывают существенную помощь в преодолении штампов и стереотипов мышления.

Одним из самых распространенных методов эвристики, является метод мозгового штурма или метод Осборна, применяемый, как правило, в группе проектировщиков, занятых разработкой общей идеи. Журналист и специалист в области PR Алекс Осборн (1888-1966) в 1942 году издал книгу «How to “Think Up"», где описал метод «мозгового штурма» (erainstorming), впрочем, практиковался им ещё в конце 1930-х. Затем Осборн модифицировал свой метод в книге 1953 года «Прикладное воображение: принципы и процедуры творческого решения проблемы» [4].

Метод Осборна включает три этапа - предварительный, основной, экспертный. (Табл. 1)

\begin{tabular}{|l|l|l|}
\hline \multicolumn{1}{|c|}{ Предварительный } & \multicolumn{1}{|c|}{ Основной } & \multicolumn{1}{|c|}{ Экспертный } \\
\hline Четко & Генерация концепта: & - Группировка \\
сформулированное & - Неограниченное & - Отбор \\
техническое Задание & количество идей & - Оценка \\
& - Запрет на критику & \\
& -Абсурдные идеи & \\
& -Комбинация, & \\
& перегруппировка, & \\
& улучшение & \\
\hline
\end{tabular}

К.ф.н., доцент кафедры социологии СФУ, социолог П.А. Стариков указывает на следующие преимущества данного метода:

- «посредством совместной деятельности специалистов, которые отличаются друг от друга опытом, знаниями, видению ближайшего будущего, 
создаются необходимые условия для синергетического эффекта «,качественного умножения" знания (целое есть больше, чем набор частей)»; также новые подходы, перспективы видения и интересные аналогии возникают «на стыках различных дисциплин, областей человеческой практики» в ходе обсуждения поставленных проблем качественно отличающимися специалистами;

- доброжелательная обстановка позволяет участникам усвоить навыки критики по существу, научиться импровизировать, а также усиливает положительный настрой и доверие [5].

С переходом от кустарного к массовому производству процесс проектирования отделился от процесса производства. Это фундаментальное разделение означало, что продукт должен был быть спланирован целиком, прежде чем он мог быть сделан, что породило современный смысл дизайна, а затем профессию дизайнера. [6].

В среде художников-проектировщиков используется также метод ассоциаций, один из эффективных стимуляторов творческого воображения. Данный метод представляет собой ряд ассоциативных аллюзий, обращенных в любую область, касающуюся деятельности человека - предметную, психологическую, метафизическую, абстрактную.

Ассоциация - это связь между отдельными представлениями, при которой одно представление вызывает другое. На этой закономерности построен метод ассоциаций. Он дает наибольший эффект в том случае, если дизайнер улавливает разносторонние явления окружающей действительности и создает связи между ними и объектом своей деятельности. Например, при создании рисунков и фактуры тканей, вышивки, аппликации он использует блеск и структуру льда, структуру застывшей грязи на дороге, капли дождя на стекле, морозные рисунки на окне. При проектировании новых форм и образов костюма дизайнер может пользоваться абстрактными явлениями - музыкой, свободным потоком сознания, снами. Они дают яркий эмоциональный импульс для развития идей костюма. В качестве толчка дизайнер может использовать и психологические явления; он фокусируется на атмосфере воображаемых условий, эмоциях, которые должны ощущаться в этих условиях, и преобразует их в графические решения объекта. Освоение ассоциативного метода развивает ассоциативное мышление дизайнера и позволяет быстро находить идеи. [7]. 
Одним из перспективных методов проектирования костюма является метод эргономики, предусматривающий «проектирование новых максимально комфортных моделей, хорошо приспособленных к физическим особенностям тела человека. При этом большое внимание уделяется качественной посадке изделия на фигуре и удобной пройме, не стесняющей движения. Метод мультиплицирования подразумевает многократное использование однородных элементов при разработке формы костюма: украшение многочисленными цветами, бантами, оборками, воланами, кусочками пряжи, меха и т.д. Он позволяет создавать необычную фактуру поверхности модели одежды, привносит момент динамизма, оживления и нередко используется при модернизации морально устаревших изделий или при декорировании лаконично решенной формы» [8].

Характерным для отечественного проектирования костюма являются методы комбинаторики и трансформации, открытие которых принадлежат русским художникам-авангардистам В. Степановой, Л. Поповой, А. Родченко. Комбинаторика - метод формообразования в дизайне, основанный на поиске, исследовании и применении различных структур, а также для создания абсолютно новых форм при создании костюма. Комбинаторика содержит в себе много различных методик, используя которые художники добиваются желаемых результатов в поиске новых дизайнерских решений. $\mathrm{B}$ Большой советской энциклопедии дается следующее определение комбинаторики: «1) то же, что математический Комбинаторный анализ. 2) Раздел элементарной математики, связанный с изучением количества комбинаций, подчинённых тем или иным условиям, которые можно составить из заданного конечного множества объектов (безразлично, какой природы; это могут быть буквы, цифры, какие-либо предметы и т.п.) [9].

На основе системного анализа, конструктивисты разработали комбинаторные методы проектирования орнамента и формы костюма, которые впоследствии легли в основу векторных графических программ.

В современном проектировании костюма, комбинированные методы включают в себя следующие направления:

1. комбинирование простейших геометрических форм;

2. трансформацию декоративных элементов;

3. комбинирование готовых стандартных объектов;

4. проектирования костюма оверсайз; 
5. проектирование раппортных материалов;

6. модульное проектирование;

7. комбинирование структурных членений внутри формы на одной конструктивной основе;

8. создание формы костюма из единого куска ткани. [10].

Комбинаторика - метод формообразования в дизайне, основанный на поиске, исследовании и применении закономерностей вариантного изменения пространственных, конструктивных, функциональных и графических структур, а также на способах проектирования объектов дизайна из типизированных элементов. Если сказать проще, то комбинаторика комбинирование различными способами форм и их элементов или вариантный поиск, который можно подразделить в проектировании на ряд основных приемов:

Комбинирование элементов на плоскости при создании текстильных композиций, раппортных тканей или трикотажных полотен;

Комбинирование типизированных стандартных элементов (модулей) при создании целостной формы;

Комбинирование деталей, пропорциональных членений внутри определенной формы (по одной конструктивной основе или базовой форме).

\section{Выводы}

Комбинаторика «оперирует» определенными приемами комбинирования: перестановкой, вставкой, группировкой, переворотом, организацией ритмов. Например, прием перестановки, или эвристическое комбинирование, предполагает изменение элементов, их замену. Этот прием получил широкое применение в проектной практике как более простой и дающий достаточно неожиданные результаты. Его можно охарактеризовать как комбинаторный поиск компоновочных решений. Этот прием часто используется при вариантном применении деталей изделия на одной конструктивной основе, при компоновке деталей одежды по всему изделию, при замене одних деталей другими. Например, замена воротников карманами, поясами, сумками, трансформирующимися полотнами в виде квадратов, треугольников, кругов и т.д. Авангардисты в моде с успехом используют эвристические и комбинаторные методы проектирования, так как в процессе свою первоначальную идею можно довести до гротеска, абсурда, и потом найти в этом рациональное зерно решения. 


\section{Список литературы}

1. Уваров В.Д., Айвазян К.А. Использование таписсерии в современном интерьере. // Бизнес и дизайн ревю. 2020. № 3 (19). С. 9.

2. Уваров В.Д. Нунех А.Ф. Влияние запаха на потребителей в интерьерах торговых пространств и использование ароматизированной таписсерии. Сборник статей XVIII Международной научно-практической конференции «Фундаментальные и прикладные науки сегодня» North Charleston. USA. 2019 - том 2, С.10-17.

3. Буш. Г.Я., Эвристика, в Словаре: Современная западная философия/Состав и отв. Редакторы Малахов В. С., Филатов В. П., М., «Политиздат»,1991г., 385 с.

4. Латыпов Н.Н., Ёлкин С.В., Гаврилов Д.А. Инженерная эвристика / под. ред. А.А. Вассермана. - М.: Астрель, 2012. - 320 с., ил.

5. Стариков П.А. Пиковые переживания и технологии творчества: учебное пособие. - Красноярск филиал НОУ ВПО Санкт-Петербургский институт внешнеэкономических связей, экономики и права в г. Красноярске, 2011. $-92 \mathrm{c}$.

6. Уваров В.Д., Нунех А.Ф. Художественный образ в дизайне и таписсерии // Проектная культура и качество жизни. 2018. № 11. - С.55-64.

7. Благова Т.Ю. Эвристические методы в дизайне одежды: Учебнометодическое пособие. - Благовещенск: Амурский государственный университет, 2006. - С. 5.

8. Киселева Т.В., Танченко В.А. Актуальные методы творческой деятельности в дизайне одежды, Материалы 66-ой Научно-практической конференции преподавателей и студентов. 2016, С. 56-58.

9. Большая советская энциклопедия. Электронный ресурс. https://rusbse.slovaronline.com/ (дата обращения 27.02.2021).

10.Netto E. Lehrbuch der Combinatorik, 2 Aufl., Lpz. - B., 1927. 230 p.

(C) В.В. Джанибекян, В.Д. Уваров, 2021 